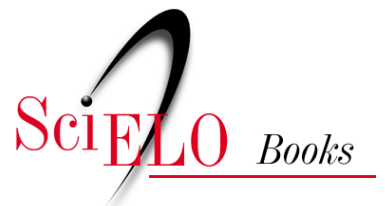

\title{
EDUFU
}

\section{A infância e seu processo educativo em Comenius}

\author{
João Luiz Gasparin
}

\section{SciELO Books / SciELO Livros / SciELO Libros}

GASPARIN, J.L. A infância e seu processo educativo em Comenius. In: BOTO, C., ed. Clássicos do pensamento pedagógico: olhares entrecruzados [online]. Uberlândia: EDUFU, 2019, pp. 27-42. História, Pensamento, Educação collection.

Novas Investigações series, vol. 9. ISBN: 978-65-5824-027-3. Available from: http://books.scielo.org/id/fjnhs/pdf/boto9786558240273-03.pdf. https://doi.org/10.14393/edufu-978-85$7078-472-8$.

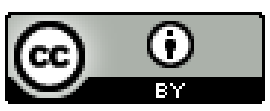

All the contents of this work, except where otherwise noted, is licensed under a Creative Commons Attribution 4.0 International license.

Todo o conteúdo deste trabalho, exceto quando houver ressalva, é publicado sob a licença Creative Commons Atribição 4.0.

Todo el contenido de esta obra, excepto donde se indique lo contrario, está bajo licencia de la licencia Creative Commons Reconocimento 4.0. 


\title{
A infância e seu processo educativo em Comenius
}

\author{
João Luiz Gasparin
}

\section{Comenius: dados biográficos}

A obra de um pensador é sempre mais facilmente compreendida quando se tem presente o contexto físico, social e histórico em que o autor viveu, pois o tempo e o espaço determinam, em boa medida, sua produção intelectual. A subjetividade, que apreende o real de forma peculiar, sofre a interferência do entorno. Os escritos expressam as características individuais, mas ao mesmo tempo traduzem o conteúdo histórico-social daquele período. Assim, ao apresentar alguns dados biográficos de Comenius para melhor compreender seu pensamento, situamos o autor e sua obra no século XVII, na Europa.

João Amós Comenius nasceu em 28 de março de 1592, em Nivnice, na Morávia, região pertencente ao Reino da antiga Boêmia, hoje República Tcheca. Sua família fazia parte do grupo religioso denominado Unidade dos Irmãos Boêmios, que seguia uma moral austera e tinha a Bíblia como base e regra de fé. Nas escolas da Congregação, o ensino era ministrado em língua vernácula, enquanto nas demais ainda predominava o ensino em língua latina. Em 1611, havendo concluído os estudos secundários em sua pátria e tendo em vista o ministério eclesiástico, Comenius foi envido à Alemanha, onde 
se matriculou na Universidade Calvinista de Herborn, transferindose depois para a Universidade de Heidelberg, onde concluiu seus estudos. Em 1614, retornando à sua pátria, assumiu a função de professor na escola latina onde havia estudado antes de ingressar na universidade. Tornou-se pastor da Unidade dos Irmãos e reitor das escolas pertencentes a eles. Mais tarde, foi elevado ao posto de bispo e arcebispo, os cargos mais elevados da Congregação. Estava sempre atento ao ensino e à vida eclesiástica, sem descuidar dos acontecimentos políticos que afetavam seu povo. Participou de todas as vicissitudes políticas da Guerra do Trinta Anos, iniciada em 1618 , bem como de todos os percalços religiosos entre protestantes e católicos, tornando-se um peregrino permanente, cuidando de sua comunidade religiosa. Para não abjurar de sua fé protestante, ele e sua congregação foram obrigados a exilar-se em Lezno, na Polônia, onde se uniram a um grupo mais antigo de irmãos também exilados. Lá escreveu sua obra mais conhecida, Didática magna. Desejava que essa obra fosse um instrumento de reconstrução das escolas e de sua pátria, quando a ela retornasse. Didática magna expressa bem o momento da passagem gradativa do feudalismo ao capitalismo. Essa obra constituise de quatro partes: 1) os fundamentos teológicos e filosóficos da educação; 2) os princípios da didática geral; 3) a didática especial das letras, ciências, artes mecânicas, moral e piedade; 4) o plano orgânico dos estudos.

Outra obra que merece destaque para compreender o seu autor como teólogo, filósofo, educador e reformador social é a Deliberação universal acerca da reforma das coisas humanas, constituída de sete livros, dentre os quais ocupa o centro a Pampaedia (Educação universal). A Deliberação destaca o espírito universalista comeniano, constituindose de uma exortação contínua à reforma universal de todas as coisas humanas, que somente poderia ser levada a efeito pela educação universal. A Pampaedia mostra que é necessário, possível e fácil educar todos os homens em todas as coisas, totalmente. Para isso se requerem, segundo o autor, escolas universais, livros universais e professores universais. 
Os ideais comenianos consistiam em reformar as escolas por meio da didática e realizar a transformação radical da sociedade tendo como instrumento básico a educação universal.

Comenius, após longa, agitada e fecunda existência, faleceu em 15 de novembro de 1670 .

\section{A infância e seu processo educativo em Comenius}

A questão que nos desafiou a elaborar o presente artigo foi assim formulada: qual a concepção de infância que se encontra nas obras educacionais comenianas e qual o processo de educação nelas proposto para as crianças?

O objetivo consistiu, portanto, em explicitar como os escritos comenianos retratam a criança no século XVII e qual a proposta educacional para essa faixa etária.

Para a elaboração do presente artigo, elegemos como fontes de investigação, entre suas obras educacionais, as que julgamos fundamentais por se referirem mais diretamente à educação universal e ao processo escolar de ensino e aprendizagem: Didática magna e Pampaedia. Da obra Didática magna destacamos os capítulos XXVII: "As instituições escolares devem ser de quatro graus, em conformidade com a idade e com o aproveitamento"; XXVIII: "Plano da escola materna"; XXIX: "Plano da escola de língua nacional". Esses capítulos tratam da infância e dos conhecimentos a serem adquiridos nesse período de vida. Em Pampaedia, o mesmo tema é abordado nos capítulos VIII: "A escola da formação pré-natal"; IX: "A escola da infância: o regaço materno"; "A escola da puerícia”.

Selecionamos também Artificii legendi et scribendi tirocinium (O aprendizado da leitura e da escrita), que trata especificamente do processo de alfabetização. Nessas obras, além dos temas gerais da educação e da didática, estão expressas as concepções de criança e de infância, bem como os processos familiares e escolares para a educação dessa faixa etária. 


\section{A infância e seu processo educativo}

Comenius (1970, p. 20) parte do pressuposto filosófico de que ao homem é possível e necessário ensinar tudo: "O homem, imagem de Deus, nasce potencialmente capaz de tudo, mas se não for instruído, permanecerá rude e privado de qualquer habilidade”.

Assim, em sua intenção de explicitar a concepção de infância, afirma que o ser humano tem necessidade de ser formado para que se torne homem. Como "animal educável", ele se tornará homem à medida que se educa. É inata no homem a aptidão para o saber, mas não o saber em si. Este deverá ser adquirido experimentalmente: "Ninguém acredite, portanto, que o homem pode verdadeiramente ser homem, a não ser aquele que aprendeu a agir como homem, isto é, aquele que foi formado naquelas virtudes que o fazem homem" (Coménio, 1976, p. 120). O homem, portanto, por meio de sua inata aptidão para tornarse homem, somente conseguirá seu intento pelo ensino, pela educação, pela cultura, pois viemos ao mundo como uma tábula rasa, sem nada saber. Assim, a todos os que nasceram homens é necessária a educação, para que se tornem verdadeiramente homens. Essa educação far-se-á com muita facilidade na primeira idade. É nesse período de vida que a criança deve ser educada.

O modelo da educação da criança, Comenius vai buscá-lo na natureza, tendo como fundamento evidente que é semelhante a condição do homem e da árvore:

Efectivamente, da mesma maneira que uma árvore de fruto (uma macieira, uma pereira, uma figueira, uma videira) pode crescer por si e por sua própria virtude, mas, sendo brava, produz frutos bravos, e para dar frutos bons e doces tem necessariamente de ser plantada, regada e podada por um agricultor perito, assim também o homem, por virtude própria, cresce com feições humanas (como também qualquer animal bruto cresce com as suas feições próprias) mas não pode crescer animal racional, sábio, honesto e piedoso, se primeiramente nele não 
se plantam os gérmens da sabedoria, da honestidade e da piedade. (Coménio, 1976, p. 127).

Como toda árvore, para que seja útil, deve ser cultivada desde pequena para que sirva a seu senhor, assim o ser humano, para que se torne tal para si e para os outros, necessitará de ser educado desde pequeno, isto é, na primeira idade. Comenius (1976) aponta as seguintes razões para que educação se inicie na infância: a incerteza de quanto tempo viveremos e que temos de nos preparar para o fim desde o início de nossa vida; o fato de que se deve começar a educação muito cedo, pois não se deve passar a vida a aprender, mas a fazer; todas as coisas, e também o homem, formam-se muito mais facilmente enquanto são tenros; os anos da infância e da juventude são os mais aptos para a formação, por isso têm longa duração; tudo o que se adquire na primeira idade torna-se firme e estável.

A educação das crianças incumbe primeiro aos pais, isto porque, como foram os autores da vida, a eles também compete a formação. Todavia, dada a dificuldade de muitos pais de educarem seus filhos, introduziu-se o costume de os confiar aos professores para que estes os formassem. Nesse processo de educação, Comenius, em Didática magna, afirma que as instituições escolares devem ser de quatro graus, conforme a idade e o aproveitamento das crianças e dos jovens. Em cada um dos graus deve ser definido um tempo para que, ao término, o educando tenha cumprido tudo o que é exigido em cada período, tomando por guia a natureza, cuja regularidade se estabelece em quatro estações. Desta maneira, divide em quatro partes distintas o tempo de formação, cada uma com seis anos e uma correspondente escola peculiar:

1) regaço materno, ou seja, a escola da infância - a primavera;

2) escola primária ou da língua vernácula, da puerícia - o verão;

3) escola de latim ou ginásio, da adolescência - o outono;

4) academia e as viagens, escola da juventude - o inverno. 
Nessas escolas, os conhecimentos devem ser ministrados em graus crescentes, mas de uma forma específica, assim expressa por Comenius (1976, p. 411): "Segundo as leis do método natural, as disciplinas não devem ser ensinadas separadamente, mas sempre todas em conjunto, da mesma forma que uma árvore cresce sempre toda em cada uma de suas partes [...]". Todavia, em cada um dos graus há distinções. Parte-se das coisas que serão ensinadas de modo geral e rudimentar, na escola materna, exercitando os sentidos externos, ascendendo para a particularidade e para os sentidos internos: "Com efeito, o verdadeiro método de formar adequadamente os espíritos consiste precisamente em que, primeiro, as coisas sejam apresentadas aos sentidos externos, aos quais impressionam imediatamente" (Comenius, 1976, p. 412).

Ao tratar dos planos de ensino em Didática magna, Comenius refere-se, em primeiro lugar, ao plano da escola materna (de 0 a 6 anos). Nela, tomando a natureza como modelo, afirma que os ramos principais de uma árvore aparecem no tronco desde os primeiros anos. Depois, apenas se desenvolvem. "Do mesmo modo, todas as coisas, em que queremos instruir um homem para utilidade de toda a vida, deverão ser-lhe plantadas logo nesta primeira escola" (Coménio, 1976, p. 415). Assim, explicita o processo de ensino e aprendizagem na escola materna, na qual deverão ser ensinados e aprendidos os conceitos gerais que servirão para toda a vida do ser humano:

Metafísica: alguma coisa, nada, existe, não existe, desta maneira, de outra maneira, onde quando.

Ciências físicas: água, terra, ar, fogo, chuva, gelo, pedra, animal; nomes do próprio corpo, que são os fundamentos da ciência natural.

Ótica: luz, trevas, sombra, cores: branco, verde, azul, preto, vermelho.

Astronomia: céu, sol, lua, estrelas e seus movimentos diários.

Geografia: monte, vale, campo, rio, aldeia, castelo, cidade.

Cronologia: hora, dia, semana, ano; primavera, verão, outono, 
inverno; ontem, amanhã, depois de amanhã.

História: recordar-se dos fatos acontecidos.

Aritmética: pouco, muito; contar até dez; notar que três é mais do que dois.

Geometria: grande, pequeno, largo e estreito, grosso e fino; entender o que é linha, cruz, círculo; medir as coisas com palmos, braçadas.

Estática: ver e pesar as coisas com balança; pesar as coisas com a mão, para saber ser são leves ou pesadas.

Artes mecânicas: transportar uma coisa de um lugar para outro; ordenar coisas; construir, destruir, unir, desunir.

Dialética: conversas se fazem por meio de perguntas e respostas. Gramática: pronunciar corretamente a língua materna - letras, sílabas, palavras.

Retórica: o gesto deve corresponder às palavras; o tom de voz deve corresponder à qualidade da conversa; distinguir a entonação de uma pergunta e de uma resposta.

Poesia: ensino de pequenos poemas.

Música: aprender salmos e hinos sagrados.

Economia doméstica: aprender os nomes dos membros da família, o nome das partes da casa, dos utensílios domésticos. Politica: as pessoas da cidade se reúnem na Câmara; existem senadores, presidente, secretário, reis, rainhas, príncipes.

Moral (ética): deve receber fundamentos solidíssimos em: temperança, limpeza, veneração, obediência, veracidade, justiça, caridade, trabalhos; aprender a falar e a manter silêncio; paciência, cortesia, urbanidade, religião e piedade (Coménio, 1976, p. 415-423).

Essas são as metas e as tarefas da escola materna tratadas em Didática magna.

Em outra obra, Pampaedia, ou seja, Educação universal, Comenius volta a tratar dos níveis escolares, mas agora abrangendo 
a universalidade da vida, e apresenta oito diferentes escolas: escola da formação pré-natal, escola da infância, escola da puerícia, escola da adolescência, escola da juventude, escola da idade adulta, escola da velhice, escola da morte. Considera, assim, que toda a vida deve ser abrangida pela escola.

Partindo do pressuposto de que os pontos principais da felicidade humana consistem em nascer bem, viver bem e morrer bem, inicia suas orientações aos pais sobre o primeiro ponto: nascer bem - a escola pré-natal.

Os cuidados com os filhos devem iniciar-se antes que eles nasçam, antes mesmo da concepção, seguindo o modelo da natureza, na qual, para semear, preparam-se primeiro o terreno e a semente; depois da semeadura, tomam-se todos os cuidados para que as ervas daninhas não prejudiquem o crescimento da nova planta.

A escola do regaço materno terá, portanto, três classes:

I. Na primeira dessas classes, ter-se-á cuidado com a futura prole à distância, preparando-se para contrair matrimônio com prudência, com honestidade e com piedade; II. A segunda classe começa com a realização do matrimónio e quando a esperança da prole está já mais próxima; III. A terceira classe ocupa-se da prole já concebida, até o nascimento. (Coménio, 1971, p. 190).

A preocupação comeniana com a educação da criança se inicia, portanto, bem antes do nascimento. Mas, de fato, a ação educativa direta dos pais sobre a criança inicia-se com seu nascimento, porque "a criancinha (infans) é um homem acabado de nascer, que entrou no mundo há pouco, inculto (rudis) em todas as coisas e que deve, por isso ser educado (erudiendus) em todas as coisas" (Coménio, 1971, p. 195). O homem rude é a matéria e o objeto de todas as escolas; o homem a ser educado é o fim da educação e de toda a atividade escolar. Dessa forma, o trabalho da escola consiste em transformar o ser humano inculto em um novo ser humano, culto: "Numa palavra, o homem 
verdadeiramente culto é aquele que, como viva imagem de Deus, apreende com a inteligência todas as coisas, exprime com a palavra todas as coisas, demonstra com factos todas as coisas, na medida em que isso é possível a uma natureza finita” (Coménio, 1971, p. 196). As sementes e os fundamentos dessa educação, portanto, devem ser lançados na infância, pois uma reforma universal de todas as coisas depende da primeira educação. Como nas sementes está toda a essência das plantas, assim na infância as faculdades estão latentes, por isso encerram maiores possibilidades educativas do que no resto dos estudos e da vida. "A infância é a primavera da vida, durante a qual não deve descurar-se a ocasião de preparar o pequeno campo do espírito" (Coménio, 1971, p. 199), no qual devem ser semeadas, desde o início, as sementes de uma vida digna, caso contrário, os vícios da primeira educação acompanhar-nos-ão durante todo o tempo de nossa existência.

$\mathrm{O}$ homem tem necessidade de uma vigilante educação desde a primeira infância. Essa educação incumbe aos pais, pois os filhos são carne de sua carne, sangue do seu sangue, espírito de seu espírito: "Em suma, importa admitir que é naturalíssimo que os filhos tenham como primeiros educadores aqueles que tiveram como pais, e aqueles que foram autores de sua vida sejam também para eles autores de uma vida honesta, santa e feliz" (Coménio, 1971, p. 202). Seguem-se, depois, os pedagogos, os preceptores, os educadores, os professores que suprem tudo o que os pais não puderem dar a seus filhos. Todavia, tanto pais quanto professores devem estar atentos para que não se percam as primeiras ocasiões da educação, pois torna-se evidente "com o exemplo de todas as coisas, que só é firme e estável aquilo de que se embebe a primeira idade, [...] de modo que as primeiras impressões agarram-se profundamente nele (o homem) e não permitem ser removidas pelas que vêm depois". Isto Comenius afirma porque parte do princípio de que "as crianças sabem em potência todas as coisas; em acto, apenas aquelas que aprenderam”. $\mathrm{Na}$ verdade, sua potência é indefinida e aberta para todas as possibilidades. Com base nela, Platão emitiu a opinião do eterno retorno do mundo e disse que "aprender é recordar" 
(Coménio, 1971, p. 205). Aqui firma-se o princípio de que algo que é repetido e incutido na infância (o hábito) transforma-se em natureza. A primeira idade é o momento da semeadura, as demais idades são os momentos da colheita. O que o homem semear no início de sua vida, isso ele colherá mais tarde.

No processo de formação da criança, Coménio (1971, p. 210) mostra que são seis as classes da educação infantil:

I. a classe puerperal, até a idade de um mês e meio;

II. a classe do aleitamento, até a idade de um ano e meio;

III. a classe dos balbucios e dos primeiros passos;

IV. a classe da linguagem e da percepção sensível;

V. a classe dos bons costumes e da piedade;

VI. a primeira escola coletiva, ou seja, a classe das primeiras letras.

Ao tratar dessas seis classes de educação das crianças, Comenius (1971, p. 217) volta a afirmar que "no homem, as raízes de todas as coisas e de todas as acções lançam-se na primeira infância. Tudo o que se faz a seguir é o efeito de um processo de desenvolvimento". Neste caso, o que vale são os bons exemplos dos mestres, porque ensinar é guiar, partindo do pressuposto de que o guia vai à frente indicando o caminho correto: "Os bons exemplos devem ser dados sem dar na vista, para que as crianças não tenham a impressão de que os adultos querem intencionalmente guiá-las, mas julguem que tudo acontece com a maior naturalidade" (Coménio, 1971, p. 218).

Complementando a fase da educação infantil, Comenius passa para a escola da puerícia, que trata da sábia e vigilante formação da juventude dos 6 aos 12 anos.

Nessa escola, como na anterior, continua afirmando que "em todos os domínios, todas as coisas que precedem determinam as que se seguem e põem-lhe o fundamento"(Coménio, 1971, p. 229). Por isso é de grande importância que cuidemos dos fundamentos, porque tudo o que as crianças ouvem, fazem, veem, tratam nessa fase da vida se torna a base sobre a qual se assentarão as demais escolas. 
Para tratar dessa escola, Comenius (1971, p. 229-230) inicia com a explicitação do conceito de criança:

As crianças (pueri) são homens de tenra idade destinadas a suceder àqueles de que agora é constituído o mundo (o Estado, a Igreja e a Escola).

São homens? Logo, devem ser educadas para a plenitude humana.

São crianças? Logo, devem ser tratadas como crianças, isto é, segundo a capacidade de compreensão própria de sua idade.

São homens de amanhã? Logo, para que realmente o venham a ser, sejam instruídas naquelas coisas que poderão vir a ser úteis aos homens.

O processo de educar as crianças deve ser gradual, segundo as etapas de sua idade, empregando o tempo da puerícia em trabalhos leves, mas que sejam prenúncio dos trabalhos mais pesados e sérios. Mesmo as coisas leves devem ser feitas com seriedade, pois as crianças são capazes disso, ainda que seja à sua maneira. Para esse trabalho são necessários professores dedicados e engenhosos: "Portanto, o professor da escola primária deve ser mais sabedor que os outros e ser remunerado com um salário maior em relação aos outros" (Coménio, 1971, p. 231). Essa escola tem como objetivo e fim possibilitar que o educando imprima agilidade ao corpo, aos sentidos e ao espírito, isto porque "as coisas que são aprendidas quando se é criança, não só são assimiladas mais rapidamente, mas também mais perfeitamente" (Coménio, 1971, p. 23). A escola da puerícia é também chamada de escola da língua nacional para a qual todos devem ser enviados, tanto meninos quanto meninas: "O objectivo e a meta da escola de língua nacional é ensinar a toda a juventude, dos seis aos doze (ou treze) anos de idade aquelas coisas que lhe serão úteis durante toda a vida" (Coménio, 1976, p. 427-428). Destacam-se entre essas coisas: ler correntemente; escrever caligraficamente, rapidamente, em conformidade com as regras gramaticais da língua vernácula; contar, medir, cantar; aprender de cor salmos e hinos sagrados; saber de cor o catecismo, as principais 
histórias e máximas das Sagradas Escrituras; aprender e pôr em prática os ensinamentos morais; aprender acerca das condições econômicas e políticas; aprender a história geral do mundo; aprender as coisas principais da cosmografia e das artes mecânicas (Coménio, 1976).

Para atingir os objetivos propostos, Coménio (1971,p.232-233) apresenta seis classes, cada uma com seu programa e seu respectivo livrinho:

I. Estreia das letras

II. O mundo em imagens

III. Ética das crianças, inferida das coisas sensíveis e da análise da natureza humana

IV. Um compêndio das histórias bíblicas

V. Uma síntese das doutrinas essenciais da Bíblia

VI. Uma coleção de adivinhas (enigmas) para crianças

Os livros propostos devem ser universais, escritos em língua nacional, contendo toda a matéria de cada classe quanto à instrução, à moral e à piedade; metódicos, fazendo avançar a inteligência de grau em grau; ornados com figuras. $\mathrm{O}$ método a ser seguido deve ser agradável, de modo que todas as coisas sejam feitas como num jogo, no qual tudo seja posto diante dos olhos.

A matéria dos livros das várias classes é a mesma, o que muda é a forma:

Portanto, em conformidade com o número de classes, estes livros serão seis, diferentes entre si, não tanto pelas matérias tratadas, como pela forma. Com efeito, todos tratarão de todas as coisas; mas o primeiro apresentará os aspectos mais gerais, mais conhecidos, mais fáceis; o seguinte promoverá a intelecção de aspectos mais especiais, mais desconhecidos e mais difíceis ou oferecerá um modo novo de considerar as mesmas coisas, para fazer saborear novas delícias aos espíritos, como dentro em breve se mostrará. (Coménio, 1976, p. 430). 
Nesses livros, tudo deve ser adaptado aos espíritos infantis, que, por natureza, são inclinados às coisas agradáveis, jocosas, lúdicas. Todavia, deve-se sempre misturar o útil ao agradável.

Os livros da escola da puerícia, em cada classe, devem ter nomes suaves, agradáveis, que encantem as crianças. Esses nomes são tirados da jardinagem, pois a escola se compara a um jardim.

Aconselha Comenius (1976) que se dediquem aos estudos dos conteúdos desses livros e das demais atividades da escola quatro horas por dia: duas de manhã, quando serão cultivadas a inteligência e a memória; duas à tarde, para exercitar as mãos e a voz. Os livros, exprimindo elegantemente todo o conteúdo a ser trabalhado, foram assim denominados por Comenius (1971):

Primeira classe - plantarium - canteiro - contendo o alfabeto, o silabário, o vocabulário, os números e pequenas preces. Essa classe terá três turmas: dos principiantes, isto é, dos que soletram; dos adiantados, que já leem; dos mais adiantados, ou seja, dos que já escrevem.

Segunda classe - seminarium - viveiro - no qual já deve estar presente um resumo de todas as coisas, isto é, da pansofia (sabedoria universal). Mesmo sem grande profundidade, essa classe deve trazer uma análise de tudo o que se deve saber: de todo o mundo, de toda a alma, de toda a Sagrada Escritura.

Terceira classe - violarium - campo de violetas - um resumo mais amplo e rico do conteúdo. Esse livro deve apresentar às crianças a ética, inferida das coisas sensíveis, especialmente da natureza, como da água, do sol, da árvore, do cão, da floresta, da rosa: "Eis, como é possível tirar, de todo o gênero de criaturas, infinitos exemplos e aplicá-los às acções humanas, com grande proveito para as crianças" (Coménio, 1971, p. 240). Nessa fase escolar, as crianças devem habituar-se a observar, a falar e a fazer tudo o que é bom para a vida presente e futura, tendo sempre em vista a felicidade eterna.

Quarta classe - rosarium - roseiral - análise do mundo da natureza, juntamente com a prática. Nessa classe, deve ser dada uma primeira explicação detalhada da Revelação Divina: Deus é o poder eterno; o 
homem é a imagem de Deus. O mundo é o domicílio, o refeitório e a escola do homem; a Sagrada Escritura é o livro de Deus; os Profetas foram homens de Deus; os Apóstolos foram homens de Deus. Quinta classe - viridarium - vergel, parque - Essa classe é o lugar apropriado para ensinar os pontos essenciais da doutrina bíblica, preparando os alunos para a piedade: "Acima de tudo, as crianças devem ser advertidas de que o olhar de Deus está sempre voltado para elas e para suas acções" (Coménio, 1971, p. 246).

Sexta classe - paradisus - jardim - ocupa-se principalmente das adivinhas, enigmas de tema religioso e moral, das fábulas e parábolas, adaptadas a essa idade.

Em todas as classes da Escola da Puerícia devem ser feitos muitos exercícios, mas deve-se cuidar para que não passem além dos sentidos. Nesse sentido, devem ser feitos exercícios de escrita: "Logo que cheguem à escrita, as crianças deverão ser exercitadas na caligrafia, no I e no II anos; na taquigrafia (escrita rápida), no III e IV anos; e na ortografia, no V e VI anos" (Coménio, 1971, p. 255).

Além das especificidades próprias de cada escola, propõe Comenius uma regra geral para todas elas:

Na Escola da Puerícia deve dar-se uma cultura geral, sem ter em consideração aquele que é nobre e aquele que é plebeu, e aquele que virá a ser artesão, comerciante, agricultor, sacerdote ou leigo, pois a escola é feita para ensinar coisas que serão úteis a todos, do mesmo modo que, no útero materno, são formados todos os membros de todos os homens. (Coménio, 1971, p. 259).

Recomenda ele que, para despertar nas crianças o desejo de aprender, deve-se utilizar a forma dialógica. Esse procedimento possibilitará que as crianças se interessem mais por fazer a experiência de todas as coisas, porque "aquele que quer ser homem inteiro, e não apenas um bocado de homem, cultive-se todo, percorrendo todo o campo das coisas" (Coménio, 1971, p. 261). 
Completando os dados sobre infância extraídos de Didática magna e Pampaedia, uma obra comeniana que merece destaque, ao tratar da educação da infância, é Artificii legendi et scribendit tirocinium (O aprendizado da leitura e da escrita). Esse livro, que tanto se refere à escola materna quanto à escola de língua vernácula, apresenta a proposta de Comenius de como deve ser conduzida a experiência de aquisição da leitura e da escrita.

Limiti (1970, p. 13) observa:

No que respeita em particular à aprendizagem da leitura, por exemplo, Comênio considerava uma inútil tortura obrigar a silabar as palavras segundo o uso das escolas de seu tempo. Ele exigia que as palavras fossem pronunciadas por inteiro, uma depois da outra, mesmo que para facilitar os principiantes as escrevesse separando as sílabas por meio de tracinhos.

Em $O$ aprendizado da leitura e da escrita, Comenius, como nas demais obras pedagógicas, demonstra um grande respeito pelo processo de amadurecimento físico e intelectual da criança. Neste sentido, volta sempre ao modelo da natureza que procede gradualmente sem pressa, mas de forma constante. Assim, o conhecimento anterior é sempre o ponto de partida para o novo conhecimento, mais amplo, mais profundo. Como a natureza se desenvolve sempre por inteiro, assim a aprendizagem da leitura não pode se dar por sílabas, mas por palavras pronunciadas inteiras.

Comenius atribui grande importância à leitura, porque, segundo ele, o analfabeto não é um homem, mas um meio-homem, mudo, surdo e cego.

\section{Conclusão}

Em todos os momentos, a mensagem de Comenius é de alcance universal, unindo sempre o sensível ao intelectual, oferecendo à criança 
primeiro a coisa em si e depois o seu nome. Primeiro, afirma ele, dêse à criança o objeto, ou, no caso da impossibilidade de oferecer-lhe a coisa, apresente-se a imagem dela, como fez em sua obra $O$ mundo sensivel ilustrado (Orbis sensualium pictus), publicado em 1685. Depois de visto, tocado, manuseado o objeto, deve-se dizer o nome dele, fazerse a explicação, o discurso sobre ele. Deve-se partir sempre do real que impressiona os sentidos, daquilo que já se conhece para depois haver a apresentação de conhecimentos novos.

Em todos os momentos, ao tratar da formação das crianças, Comenius faz analogia entre a educação e o cultivo das plantas, concebendo uma teoria humanista e espiritualista na formação do homem, realizando o processo de aprendizagem por meio da experiência, da observação, sem punição, com diálogo, buscando formar o homem religioso em primeiro lugar, mas também o homem social, político, racional, afetivo e moral.

Em seu processo de ensino e aprendizagem, parte sempre dos sentidos que apreendem a sensorialidade dos objetos pela experiência, internalizando posteriormente as impressões que seriam interpretadas pela razão.

\section{Referências}

COMÉNIO, J. A. Pampaedia. Coimbra: Faculdade de Letras da Universidade de Coimbra, 1971.

COMÉNIO, J. A. Didáctica magna. 2. ed. Lisboa: Fundação Calouste Gulbenkian, 1976.

COMENIUS, J. A. Il tirocinio del leggere e dello scrivere. Armando Armando Editore: Roma, 1970.

COMENIUS, J. A. Orbis sensualium pictus. Praga, 1979. Fac-simile da edição de 1685 .

LIMITI, G. Introduzione. In: COMENIUS, J. A. Il tirocinio del leggere e dello scrivere. Roma: Armando Armando Editore, 1970. 